Dr. SpIEckers Beerdigung fuhr und die Grenze passierte, kam es mir plötzlich in den Sinn, wie schnell man sich an diese internationalen Zusammentreffen gewöhnt. Jedesmal, wenn wir die Grenze überquerten, kamen wir auch wieder zurück nach Hause. Eine Grenze jedoch, die Grenze des Lebens, können wir nur einmal überqueren. Am 6. Juni ist Dietmar Spiecker über diese letzte Grenze ins Jenseits abberufen worden. Wir alle betrauern sehr, daß er in so jungen Jahren seine Familie verlassen mußte. Ex ist uns vorausgegangen zu dem, der auch für uns einen Platz bereithält.

Einer seiner ausländischen Freunde

J. L. van HAAFten

\title{
11. Kongreß des Internationalen Ringes der Jagdwissenschaftler
}

\author{
(XIth International Congress of Game Biologists)
}

Der XI. Kongreß findet in der Zeit vom 3.-7. September 1973 in Stockholm statt. Das Leitthema lautet:

\author{
Wild und Umwelt \\ (Game populations and environmental factors)
}

Hierunter fallen die Themen:

1. Bestandesökologie von Wildarten

(Population ecology of game species)

2. Menschliche Einflüsse auf das Wild

(Human impact on game species)

3. Methoden der Wildforschung

(Methods in game research)

Interessenten wollen sich an den XIth International Congress of Game Biologists, c/o Reso Congress Service, S-105 24 Stockholm, Schweden, wenden und dort Unterlagen anfordern.

F. NÜSSLEIN

\section{REFERATE}

Referenten: v. Berg (v. Bg.), v.Braunschweig (v. B.), Nüsslein (Nn.), Rieck (Rk.), Stahl (St.)

\section{Wildkunde und Pathologie}

Andersen, J.; Jensen, B.: The weight of the eye lens in the European hares of known age (Das Gewicht der Augenlinse bei Europäischen Feldhasen bekannten Alters). Acta theriol., 17, 8 (Engl. m. poln. Zsfg.).

Auf der 100 ha großen Insel Illumö in Dänemark wurde im Winter die Hasenpopulation jährlich vollzählig mit Netzen gefangen und markiert. Der Besatz lag zwischen 100 und 300 erwachsenen Hasen. Die jeweils gefangenen ungezeichneten Hasen waren also Junghasen des laufenden Jahres. Im November 1970 wurden 90 Hasen bekannten Alters gefangen oder abgeschossen, um u. a. das Linsengewicht als Altersmerkmal zu untersuchen, ihr Alter lag zwischen jung und $4 \frac{1}{2}$ Jahren. Die Gewichtsdifferenz $z$ wischen frisch und nach 4 Tagen entnommenen und konservierten Linsen lag bei nur 1-2\% im Durchschnitt, es können also Hasenstrecken auch noch einige Tage nach der Erbeutung analysiert werden. 